\title{
Editoriali
}

\section{Lessons from recent research on depression in primary care ${ }^{1}$}

\author{
GREGORY E. SIMON and EVETTE LUDMAN
}

The prevalence and impact of common psychological disorders in primary care were first described by Michael Shepherd (Shepherd, 1973) and David Goldberg (Goldberg \& Blackwell, 1970) approximately 30 years ago. In 1985, Schurman et al. (1985) referred to primary health care in the US as a "hidden mental health network". Given the sheer volume of recent research on depression in primary care (approximately 900 publications referenced in MEDLINE since 1993), we can no longer describe mental health problems in primary care as hidden. In this review, we attempt to summarize this recent research. Our focus is on effective clinical programs for the management of depression among primary care patients.

\section{CLARIFYING THE PROBLEM}

Overwhelming epidemiologic evidence documents the prevalence and burden of depressive disorders among primary care patients. While prevalence of depressive disorder in different primary care populations ranges from 5 to $20 \%$, depression is certainly one of the most common chronic health conditions managed in primary care (Üstün \& Sartorius, 1995; (Spitzer et al., 1994). Depression among primary care patients is associated with

\footnotetext{
Indirizzo per la corrispondenza: Dr. Gregory E. Simon, Center for Health Studies, Group Health Cooperative, 1730 Minor Ave.1600, Seattle, WA 98112 (USA).

Fax +1 206-287.2871

E-mail: simon.g@ghc.org

'Preparation of this manuscript was supported by grants MH51338 and MH41739 from the US National Institute of Mental Health.
}

a tremendous burden of functional impairment and disability (Ormel et al., 1994; VonKorff et al., 1992; Spitzer et al., 1995; Counseling Versus Antidepressants in Primary Care Study Group, 1999). Even in those countries with the greatest supply of mental health providers, primary care physicians are responsible for the majority of depression treatment (Regier et al., 1993; Pincus et al., 1998).

Considerable research has examined the problem of under-recognition of depression by primary care physicians. While some studies have reported recognition rates as low as $10 \%$, studies using structured diagnostic assessments to identify depressive disorder typically report recognition rates of 40 to $50 \%$. The World Health Organization's Psychological Problems in General Health Care (PPGHC) study found an overall recognition rate of approximately $50 \%$, but also found that recognition rates varied significantly across study sites (Üstün \& Sartorius, 1995). Recognition was higher at sites with a more personal or patient-centered style of primary care (e.g. ongoing care by a single personal physician). Recognition of depression is influenced by characteristics of the physician (Goldberg et al., 1993; Marks et al., 1979; Millar \& Goldberg, 1991) (e.g. more patient-centered interviewing style, greater interest in management of mental health problems) and characteristics of the patient (e.g. presentation with a psychological complaint) (Simon $e t$ al., 1999; Bridges \& Goldberg, 1985). The most consistent finding has been the relationship between physician recognition and severity of depression (Simon et al., 1999; Coyne et al., 1995).

A similar volume of research has examined the quality and continuity of depression treatment received by primary care patients. Given that pharmacotherapy is the 
treatment most commonly provided in primary care, most of this research has examined the process of antidepressant treatment. The probability that patients with recognized depression will receive any antidepressant treatment shows considerable cross-national variation - with high rates of benzodiazepine use in some settings ( $\mathrm{Lin}$ den et al., 1999). Among patients beginning treatment with antidepressants, research in the US and Western Europe has consistently found that over one-third discontinue treatment within a few weeks and that nearly half of those continuing treatment receive antidepressant doses less than those generally considered effective (Simon et al., 1993; Wells et al., 1994; Dunn et al., 1999). Consequently, fewer than half of patients beginning antidepressant treatment receive "adequate" treatment (as assessed by both dose and duration). Furthermore, the frequency of follow-up care following an initial antidepressant prescription typically falls far short of recommended levels - with a typical patient making only one or two follow-up visits over the next several months (Katz et al., 1998).

While recent research shows significant shortcomings in both recognition of depression and quality of antidepressant treatment, findings in these two areas show one important difference. Probability of recognition of depression is strongly related to severity of illness - so one might argue that non-recognition is sometimes an appropriate clinical response (Coyne et al., 1995). In contrast, shortcomings in quality of pharmacotherapy and follow-up care appear unrelated to clinical need - and cannot be considered clinically "rational" (Simon et al., 1995; Revicki et al., 1998). Several follow-up studies have reported that primary care patients with unrecognized depression actually experience better outcomes than those recognized - suggesting a fair degree of treatment matching (i.e. patients with better prognosis are more likely to go unrecognized). A review of several papers published from the WHO PPGHC study allows a closer look at the relationship between recognition and patient outcomes. Analyses of data from the US (Simon \& VonKorff, 1995) and Dutch (Tiemens et al., 1996) sites compared outcomes of patients recognized and not recognized as having any mental disorder. Unrecognized patients were less depressed at baseline and improved at least as much as those recognized. A later analysis (including patients from all sites) examined specific recognition (i.e. recognition accompanied by a specific diagnosis of depression) (Simon et al., 1999). Using this standard, recognition was associated with a slightly greater rate of improvement. Finally, Goldberg et al. (1998a) examined outcomes of patients receiving at least one prescription for antidepressant medication (i.e. a depression-specific treatment). Recognition followed by treatment was associated with a significantly greater improvement at 3 months.

\section{THE EFFECTIVENESS OF TREATMENT}

When the US Agency for Health Care Policy and Research published its 1992 guidelines for depression treatment in primary care (Depression Guideline Panel, 1993), few studies directly supported the effectiveness of standard depression treatments among primary care patients. Most randomized trials demonstrating the effectiveness of pharmacotherapy and psychotherapy had been conducted among selected samples of specialty patients. The AHCPR guideline panel acknowledged the differences between primary care and specialty patients, but argued that treatments shown to be effective in specialty practice should also prove effective in primary care. Numerous randomized trials over the last five years support that claim.

Strong evidence supports the effectiveness of antidepressant pharmacotherapy in primary care. At least $\mathbf{3 0}$ randomized trials have examined this question, and effectiveness of antidepressant medication among primary care patients appears at least as great as among specialty patients (Trivedi et al., in press; Schulberg et al., 1998; Mulrow et al., 1998). Because more primary care patients treated with antidepressants may suffer from mild or moderate depression, several primary care studies have examined the effectiveness of pharmacotherapy in less severe depressive disorders. Antidepressant medication appears superior to placebo among patients with at least moderate symptoms (e.g. Hamilton Depression Rating Scale scores of 13 or more, meeting or exceeding DSMIV criteria for major depressive episode), but not among those with less severe symptoms (Paykel et al., 1988; Katon et al., 1995; Barrett et al., 1999). Reasonably good evidence from specialty studies supports the use of pharmacotherapy in dysthymia (Thase et al., 1996). Among primary care patients with minor depression (i.e. less severe depression of relatively brief duration), probability of recovery with antidepressant treatment is still high but not significantly higher than probability of improvement with placebo and/or supportive care.

Growing evidence supports the effectiveness of structured psychotherapy programs provided in primary care. In a randomized trial among US urban primary care patients, Schulberg et al. (1996) found that manual-based Interpersonal Psychotherapy was clearly superior to 
usual primary care. In the Edinburgh Primary Care Depression Study, clinical improvement during cognitive therapy was similar to that seen in specialty trials (Scott \& Freeman, 1992). Mynor-Wallis et al. (1995) demonstrated that a structured 6-session problem solving psychotherapy program (provided by either specialists or specially trained general practitioners) was superior to a pillplacebo control treatment. Katon and colleagues have evaluated a 4- to 6-session psychoeducational program (including elements of behavioral activation and cognitive restructuring) as an adjunct to antidepressant pharmacotherapy in primary care. Compared to care as usual, this psychologist collaborative care model resulted in significantly better medication adherence and clinical outcomes (Katon et al., 1996).

The argument for combined treatment (psychotherapy and pharmacotherapy) may actually be stronger in primary care populations than in specialty care. Specialtybased studies have examined the benefits of combined treatment vs. pharmacotherapy alone. These data have been variously interpreted as showing either no significant benefit of combined treatment (Depression Guideline Panel, 1993; Conte et al., 1986) or a modest benefit of combined treatment among those with more severe depression (Thase et al., 1997). In any case, the additional benefits of combined treatment are small compared to the difference between active treatment and placebo. These studies, however, have examined the addition of psychotherapy to the type of pharmacotherapy typically provided in specialty clinical trials (e.g. weekly or biweekly visits, strict treatment protocols, high rates of adherence). As we discus above, pharmacotherapy provided in everyday primary care practice differs markedly from that in specialty clinical trials (sporadic follow-up care, large variability in dosing, frequent non-adherence). Given that typical primary care pharmacotherapy provides a much lower level of follow-up and supportive contact, it is reasonable to suppose that a structured psychotherapy program would offer significant additional benefit. Some recent studies of depression treatment programs in primary care could be viewed as evidence for this position. The psychologist Collaborative Care study by Katon et al. (1996), described below, demonstrated the benefits of a brief, structured psychotherapy program provided as an adjunct to antidepressant treatment in primary care. In a recent pilot study, Tutty et al. (2000) found that a 6-session cognitive-behavioral psychotherapy program provided by telephone was a significant addition to antidepressant pharmacotherapy by the primary care physician. A recent randomized trial by Hunkeler $e t$ al. (in press), also described below, found significant benefit from a telephone monitoring and support program among primary care patients beginning antidepressant treatment. While all three of these programs may have also improved adherence to antidepressant treatment, we suspect that at least a portion of the clinical benefit resulted from the psychotherapy provided.

\section{THE CHALLENGES OF IMPLEMENTATION}

Despite strong evidence for the effectiveness of depression treatment in primary care, everyday management typically falls short of expert guidelines. As we discuss above, studies of depression treatment in primary care demonstrate high rates of failure at several key steps in the process of depression treatment including: failure to recognize depression, failure to initiate a depression-specific treatment (either psychotherapy or pharmacotherapy), inadequate frequency of follow-up visits (for both pharmacotherapy and psychotherapy), and inadequate dose and/or duration of pharmacotherapy. The combined effect of these multiple shortcomings is that fewer than $25 \%$ of primary care patients with depressive disorders receive recommended levels of treatment. We should also emphasize that most available data are drawn from the US and UK - where rates of recognition and rates of antidepressant use are relatively high. Overall rates of adequate treatment are certainly lower in countries where depression is less often recognized or where prescribing of benzodiazepines exceeds prescribing of antidepressants. Over the last decade, a number of studies (most of them randomized trials) have evaluated various strategies to increase rates of adequate depression treatment in everyday primary care practice.

Several studies suggest that isolated attempts to increase recognition of depression are unlikely to improve patient outcomes. In a randomized trial among UK primary care patients, Dowrick \& Buchan (1995) found that feedback of depression screening scores to treating physicians had no impact on patient outcomes. In a randomized trial among elderly US primary care patients, Callahan et al. (1994) found that feedback of depression screening and management recommendations did not improve clinical outcomes. Katon et al. (1992) found a similar result in a study of depressed "high utilizers" of medical care. In both the Katon and Callahan studies, feedback of screening results did increase the likelihood that primary care physicians would record diagnoses of depression and initiate antidepressant treatment. The resulting treatment, however, was not sufficient to affect clinical outcomes. In contrast with results of these scree- 
ning interventions, programs of screening followed by systematic treatment have been clearly demonstrated to improve patient outcomes (Schulberg et al., 1996; Katzelnick et al., 2000). We conclude that increasing recognition of depression is a necessary, but not sufficient, step toward providing effective depression treatment in primary care.

Intervention programs limited to physician education have also been generally disappointing. In a followup study of physicians participating in the Katon Collaborative Care studies (discussed below), Lin et al. (1997) found no evidence for a lasting effect of physician training on either quality of care or patient outcomes. Goldberg et al. (1998b) found that a training and quality improvement program including both academic detailing and continuous quality improvement groups (methods proven effective in other previous studies) also had some effect on medication selection but no effect on patient outcomes. Using a before-after design, Tiemens et al. (1999) examined the effects of a training program for Dutch general practitioners. Training resulted in more appropriate use of antidepressants and better short-term outcomes, but training effects faded by one year. Thompson et al. (2000) found that a guideline-based educational program for British general practitioners had no effect on either recognition of depression or patient outcomes. We conclude that interventions limited to physician training may have positive effects on initial prescribing decisions, but the central shortcomings in primary care management of depression (frequent treatment discontinuation, erratic follow-up care) are beyond the reach of physician education programs.

A number of randomized trials have examined more direct strategies to improve the quality and intensity of antidepressant pharmacotherapy in primary care. These interventions have varied widely in both type and intensity. Programs directed at physicians (i.e. no direct contact with patients) have generally proved disappointing. Rollman et al. (1999) found that a system of physician reminders and instructions delivered through an electronic medical record had no significant impact on patient outcomes. We have recently evaluated a system of feedback and treatment recommendations also based on available computerized data (outpatient visits and prescription refills) (Simon et al., 2000). This program also had no significant effect on quality of pharmacotherapy or patient outcomes. In contrast with these unsuccessful efforts directed at physicians, several patient-directed interventions have been proven superior to usual primary care management.
Schulberg et al. (1996) evaluated a program of guideline-based pharmacotherapy provided by specially trained primary care physicians following a structured protocol - including frequent visits and blood level monitoring. Clinical outcomes for patients in the structured pharmacotherapy program were clearly superior to those for patient receiving usual care (many of whom went untreated). Katon et al. $(1995 ; 1996 ; 1999)$ have developed and tested Collaborative Care programs including mental health specialists (psychiatrists or psychologists) supporting primary care physicians through education, consultation, and collaborative practice. These programs were shown to improve both quality of pharmacotherapy and patient outcomes - though significant clinical benefits were not seen in patients with mild depression. Both the Schulberg and Katon programs included direct treatment by specialized providers located in the primary care clinic. Two subsequent studies - one by our group (Simon et al., 2000) and one by Hunkeler $e t$ al. (in press) - have tested telephone-based programs to improve the quality of antidepressant pharmacotherapy in primary care. Both programs included brief scheduled telephone contacts for support, monitoring of medication adherence, and monitoring of treatment response. Both programs led to modest, but significant, improvements in clinical outcomes compared to usual primary care. Peveler et al. (1999) have recently reported that brief medication counselling provided by a nurse resulted in significantly greater adherence to antidepressant treatment. For patients with more severe depression who were also prescribed adequate doses of medication, this greater adherence was associated with improved clinical outcomes. We identify three elements common to most of these successful intervention programs: patient education and activation, systematic and active follow-up care, and use of evidence-based treatment algorithms. We also conclude that size of clinical benefit was generally commensurate with the intensity (and expense) of the intervention program.

Several studies have evaluated efforts to increase the availability of effective depression-specific psychotherapy. Some of the randomized trials cited earlier regarding the effectiveness of psychotherapy in primary care might also be viewed as studies of implementation. Schulberg et al. (1996) found that $14 \%$ of patients randomized to Interpersonal Psychotherapy did not attend the initial session and an additional $31 \%$ dropped out prior to completing 16 sessions. Katon et al. (1996) found that $6 \%$ of patients randomized to the psychologist Collaborative Care program did not attend the initial session and an additional $6 \%$ dropped out prior to

Epidemiologia e Psichiatria Sociale, 9, 3, 2000 
completion of four sessions. Mynors-Wallis et al. (1995) reported that $93 \%$ of patients randomized to problemsolving psychotherapy completed the planned six sessions. In contrast with these generally high rates of participation, studies depending on referral to community psychotherapists have reported much lower rates of treatment initiation and treatment completion (Wells, 1997; Rost $e t$ al., 1998). We conclude that participation is greater for briefer interventions provided in the primary care setting. Referral to a separate specialty practice is a major barrier to treatment initiation.

All efforts to provide effective depression treatment in primary care face two common challenges: increasing initial acceptance of depression treatment and maintaining adherence to treatment over time. Several factors contribute to difficulties with initial acceptance and adherence including: the stigma associated with depression, exaggerated fears regarding treatment, treatment side-effects, as well as the inertia and loss of motivation which characterize depression. Effective depression treatment programs must include elements and strategies to address these barriers: education focused on patient activation, systematic and proactive followup by staff specifically responsible for continuing care, and on-going support for treatment adherence and behavior change. In general, participation is greater for briefer interventions provided in a convenient fashion (e.g. counseling provided directly in the primary care setting). The success of telephone-based monitoring and counseling programs further suggests that some of patients' barriers leading to treatment 'drop-out', (e.g., inconvenience of multi-session specialty care appointments, perceived stigma of receiving mental health care), can be overcome through the re-organization of care. While traditional mental health care has left followup care to patients' initiative, overcoming barriers to adherence requires a more active and persistent approach.

Overcoming barriers to adherence also requires that the clinical content of interventions address individuals' needs, concerns, and priorities in a patient-centered fashion. Studies in the fields of substance abuse and health behavior change have identified essential elements of patient-centered interventions. Effective adherence-building interventions are those that focus on patients' readiness to engage in a particular behavior, their personal motivations and barriers, and their confidence in taking specific steps toward the desired behavior change. Daley et al. (1998) demonstrated that an intervention based on the motivational interviewing techniques described by Miller and colleagues (Hester \& Miller, 1995) improved treatment adherence and com- pletion among a group of patients with comorbid depressive disorder and cocaine dependence. Such brief motivational enhancement strategies delivered in primary care may aid in efforts to promote or maintain adherence to evidence-based treatments.

\section{CONCLUSIONS}

Shortcomings in the current management of depression do not reflect a lack of proven effective treatments. As we discuss above, abundant evidence supports the effectiveness of depression-specific treatments (both pharmacotherapy and psychotherapy) among depressed primary care patients. These treatments (antidepressant pharmacotherapy, cognitive-behavioral psychotherapy, interpersonal psychotherapy) have been proven effective and available for clinical use for at least 15 years. Studies in the US and Western Europe still find, however, that most primary care patients with depressive disorders have little or no exposure to effective treatments. We can only assume that rates of appropriate treatment are much lower in countries with fewer mental health treatment resources. The specialty perspective leads to a focus on treatment resistant depression - patients with persistent depression despite optimal treatment. At the population level, however, the proportion of those with depressive disorders receiving optimal treatment is almost inconsequential.

Our review of successful and unsuccessful depression treatment programs leads to some surprisingly simple conclusions. First, identification of depressive disorders is of little value unless proven effective treatments are readily available. Second, treatments are generally effective when they are of adequate intensity and duration and ineffective when they are not. Third, premature treatment discontinuation is the rule rather than the exception. Any treatment program is unlikely to succeed without outreach and active follow-up. These conclusions could be condensed even further to a single motto for depression treatment in primary care: the greatest gains are likely to come from doing the simple things well.

\section{REFERENCES}

Barrett J.E., Williams J.W. Jr, Oxman T.E., Katon W., Frank E., Hegel M.T., Sullivan M. \& Schulberg H.C. (1999). The Treatment Effectiveness Project. A comparison of the effectiveness of paroxetine, problem-solving therapy, and placebo in the treatment of minor depression and dysthymia in primary care patients: background and research plan. General Hospital Psychiatry 21, 260-273. 
Bridges K.W. \& Goldberg D.P. (1985). Somatic presentations of DSMIII psychiatric disorders in primary care. Journal of Psychosomatic Research 29, 563-569.

Callahan C.M., Hendrie H.C., Dittus R.S., Brater D.C., Hui S.L. \& Tierney W.M. (1994). Improving treatment of late life depression in primary care: A randomized clinical trial. Journal of the American Geriatric Society 42, 839-846.

Conte H.R., Plutchik R., Wild K.V. \& Karasu T.B. (1986). Combined psychotherapy and pharmacotherapy for depression. A systematic analysis of the evidence. Archives of General Psychiatry 43, 471479.

Counseling Versus Antidepressants in Primary Care Study Group (1999). How disabling is depression? Evidence from a primary care sample. British Journal of General Practice 49, 95-98.

Coyne J.C., Schwenk T.L. \& Fechner-Bates S. (1995). Non-detection of depression by primary care physicians reconsidered. General Hospital Psychiatry 17, 3-12.

Daley D.C., Salloum I.M., Zuckoff A., Dirisci L. \& Thase M.E. (1998). Increasing treatment adherence among outpatients with depression and cocaine dependence: results of a pilot study. American Journal of Psychiatry 155, 1611-1613.

Depression Guideline Panel (1993). Clinical Practice Guideline Number 5: Depression in Primary Care. Volume 1: Detection and Diagnosis. 93. Rockville, MD, US Dept of Health and Human Services, Agency for Health Policy and Research. AHCPR Publication No 93-0550.

Dowrick C. \& Buchan I. (1995). Twelve month outcome of depression in general practice: does detection or disclosure make a difference? British Medical Journal 311, 1274-1277.

Dunn R.L., Donoghue J.M., Osminkowski R.J., Stephenson D. \& Hylan T.R. (1999). Longitudinal patterns of antidepressant prescribing in primary care in the UK: comparison with treatment guidelines. Journal of Psychopharmacology 13, 136-143.

Goldberg D.P. \& Blackwell B. (1970). Psychiatric illness in general practice: a detailed study using a new method of case identification. British Medical Journal 23;1(707), 439-432.

Goldberg D.P., Jenkins L., Millar T. \& Faragher E.B. (1993). The ability of trainee general practitioners to identify psychological distress among their patients. Psychological Medicine 23, 185-193.

Goldberg D.P., Privett M., Üstün T.B., Simon G. \& Linden M. (1998a). The effects of detection and treatment on the outcome of major depression in primary care: a naturalistic study in 15 cities. British Journal of General Practice 48, 1840-1844.

Goldberg H.I., Wagner E.H., Fihn S.D., Martin D.P., Horowitz C.R., Chistensen D.B., Cheadle A.D., Diehr P. \& Simon G. (1998b). A randomized controlled trial of $\mathrm{CQI}$ teams and Academic Detailing: can they alter compliance with guidelines? Joint Commission Journal on Quality Improvement 24, 130-142.

Hester R. \& Miller W. (1995). Increasing motivation to change. In Handbook of Alcoholism Treatment Approaches (ed. R. Hester and W.R. Miller), pp. 89-104. Allyn and Bacon: Boston.

Hunkeler E.M., Meresman J., Hargreaves W., Fireman B., Berman W., Kirsch A., Groebe J., Braden P., Getzell M., Feigenbaum P., Hurt W., Peng T. \& Salzer M. (in press). Efficacy of nurse telehealth care and peer support in augmenting treatment of depression in primary care. Archives of Family Medicine.

Katon W., VonKorff M., Lin E., Bush T., Lipscom P. \& Russo J. (1992). A randomized trial of psychiatric consultation with distressed high utilizers. General Hospital Psychiatry 14, 86-98.

Katon W., Robinson P., VonKorff M., Lin E., Bush T., Ludman E., Simon G. \& Walker E. (1996). A multifaceted intervention to im- prove treatment of depression in primary care. Archives of General Psychiatry 53, 924-932.

Katon W., Von Korff M., Lin E., Walker E., Simon G., Bush T., Robinson P. \& Russo J. (1995). Collaborative management to achieve treatment guidelines: impact on depression in primary care. Journal of American Medical Association 273, 1026-1031.

Katon W., Von Korff M., Lin E., Simon G., Walker E., Unutzer J., Bush T., Russo J. \& Ludman E. (1999). Stepped collaborative care for primary care patients with persistent symptoms of depression. Archives of General Psychiatry 56, 1109-1115.

Katz S.J., Kessler R.C., Lin E. \& Wells K.B. (1998). Medication management of depression in the United States and Canada. Journal of General Internal Medicine 13, 77-85.

Katzelnick D.J., Simon G.E., Pearson S.D., Manning W.G., Helstad C.P., Henk H.J., Cole S.M., Lin E.H., Taylor L.H. \& Kobak K.A. (2000). Randomized trial of a depression management program in high utilizers of medical care. Archives of Family Medicine 9, 345351.

Lin E., Katon W., Simon G., VonKorff M., Bush T., Rutter C., Saunders K. \& Walker E. (1997). Achieving guidelines for treatment of depression in primary care: Is physician education enough? Medical Care 35, 831-842.

Linden M, Lecrubier Y., Bellantuono C., Benkert O., Kisely S. \& Simon G. (1999). The prescribing of psychotropic drugs by primary care physicians: an international collaborative study. Journal of Clinical Psychopharmacology 19, 132-140.

Marks J.N., Goldberg D.P. \& Hillier V.F. (1979). Determinants of the ability of general practitioners to detect psychiatric illness. Psychological Medicine 9, 337-353.

Millar T. \& Goldberg D.P. (1991). Link between the ability to detect and manage emotional disorder: a study of general practitioner trainees. British Journal of General Practice 41, 357-359.

Mulrow C.D., Williams J.W. Jr, Trivedi M., Chiquette E., Aguilar C., Cornell J.E., Badgett R., Noel P.H., Lawrence V., Lee S., Luther M., Ramirez G., Richardson W.S. \& Stamm K. (1998). Treatment of depression - newer pharmacotherapies. Psychopharmacology Bulletin 34, 409-795.

Mynors-Wallis L.M., Gath D.H., LLoyd-Thomas A.R. \& Tomlinson D. (1995). Randomised controlled trial comparing problem solving treatment with amitriptyline and placebo for major depression in primary care. British Medical Journal 310, 441-445.

Ormel J., VonKorff M., «st,n T.B., Pini S., Korten A. \& Oldehinkel T. (1994). Common mental disorders and disability across cultures. Journal of American Medical Association 272, 1741-1748.

Paykel E.S., Hollyman J.A., Freeling P. \& Sedgwick P. (1988). Predictors of therapeutic benefit from amitriptyline in mild depression: A general practice placebo-controlled triak. Journal of Affective Disorders 14, 83-95.

Peveler R., George C., Kinmouth A., Campbell M. \& Thompson C. (1999). Effect of antidepressant drug counselling and information leaflets on adherence to drug treatment in primary care: randomised controlled trial. British Medical Journal 319, 612-615.

Pincus H., Tanielian T., Marcus S.C., Olfson M., Zarin D.A., Thompson J. \& Zito J. (1998). Prescribing trends in psychotropic medications: primary care, psychiatry, and other medical specialties. Journal of American Medical Association 279, 526-531.

Regier D.A., Narrow W.E., Rae D.S., Mandersheid R.W., Locke B.Z. \& Goodwin F.K. (1993). The de facto US mental and addictive disorders service system: Epidemiologic catchment area prospective 1-year prevalence rates of disorders and services. Archives of $\mathrm{Ge}$ neral Psychiatry 50, 85-94. 
Revicki D.A., Simon G.E., Chan K. \& Heiligenstein J. (1998). Depression, health-related quality of life, and medical cost outcomes of receiving recommended levels of antidepressant treatment. Journal of Family Practice 47, 446-452.

Rollman B.L., Gilbert T., Lowe H.J., Kapoor W.N. \& Schulberg H.C. (1999). The electronic medical record: Its role in disseminating depression guidelines in primary care practice. International Journal of Psychiatry in Medicine 29, 267-286.

Rost K., Nutting P., Smith J. \& Werner J. (1998). Primary care intervention improves depression outcomes. International Journal of Psychiatry in Medicine 28, 398-399.

Schulberg H.C., Block M.R., Madonia M.J., Scott C., Lave J., Rodriguez E. \& Coulehan J. (1996). Treating major depression in primary care practice: Eight-month clinical outcomes. Archives of $\mathrm{Ge}$ neral Psychiatry 53, 913-919.

Schulberg H.C., Katon W., Simon G.E. \& Rush A.J. (1998). Treating major depression in primary care practice: An update of the Agency for Health Care Policy and Research practice guidelines. Archives of General Psychiatry 55, 1121-1127.

Schurman R.A., Kramer P.D. \& Mitchell J.B. (1985). The hidden mental health network: Treatment of mental illness by nonpsychiatrist physicians. Archives of General Psychiatry 42, 89-94.

Scott A. \& Freeman C. (1992). Edinburgh primary care depression study: treatment outcome, patient satisfaction, and cost after 16 weeks. British Medical Journal 304, 883-887.

Shepherd M. (1973). The General Practice Research Unit at the Institute of Psychiatry. Psychological Medicine 3, 525-529.

Simon G.E. \& VonKorff M. (1995). Recognition, management, and outcomes of depression in primary care. Archives of Family Medicine 4, 99-105.

Simon G.E., VonKorff M., Wagner E.H. \& Barlow W. (1993). Patterns of antidepressant use in community practice. General Hospital Psychiatry 15, 399-408.

Simon G.E., Lin E.H.B., Katon W., Saunders K., VonKorff M., Walker E., Bush T. \& Robinson P. (1995). Outcomes of "inadequate" antidepressant treatment in primary care. Journal of General Internal Medicine 10, 663-670.

Simon G.E., Goldberg D., Tiemens B.G. \& Üstün T.B. (1999). Outcomes of recognized and unrecognized depression in an international primary care study. General Hospital Psychiatry 21, 97-105.

Simon G.E., VonKorff M., Rutter C. \& Wagner E. (2000). A randomized trial of monitoring, feedback, and management of care by telephone to improve treatment of depression in primary care. British Medical Journal 320, 550-554.

Spitzer R.L., Williams J.B.W., Kroenke K., Linzer M., deGruy F.V., Hahn S.R., Brody D. \& Johnson J.G. (1994). Utility of a new procedure for diagnosing mental disorders in primary care: The PRI-
ME-MD 1000 study. Journal of American Medical Association 272, $1749-1756$.

Spitzer R.L., Kroenke K., Linzer M., Hahn S.R., Williams J.B.W., DeGruy F.V., Brody D. \& Davies M. (1995). Health-related quality of life in primary care patients with mental disorders. Journal of American Medical Association 274, 1511-1517.

Thase M.E., Fava M., Halbreich U., Kocsis J.H., Koran L., Davidson J., Rosenbaum J. \& Harrison W. (1996). A placebo-controlled, randomized trial comparing sertraline and imipramine for the treatment of dysthymia. Archives of General Psychiatry 53, 777 784.

Thase M., Greenhouse J., Frank E., Reynolds C., Pilkonis P., Hurley K., Grochocinski J. \& Kupfer D. (1997). Treatment of major depression with psychotherapy or psychotherapy-pharmacotherapy combinations. Archives of General Psychiatry 54, 1009-1015.

Thompson C., Kinmouth A.L., Stevens L., Peveler R.C., Ostler K.J., Pickering R.M., Baker N.G., Henson A., Preece J., Cooper D.\& Campbell M.J. (2000). Effects of a clinical-practice guideline and practice-based education on detection and outcome of depression in primary care: Hampshire Depression Project randomised controlled trial. Lancet 355, 185-191.

Tiemens B.G., Ormel J. \& Simon G.E. (1996). Occurrence, recognition, and outcomes of psychological disorders in primary care. American Journal of Psychiatry 153, 636-644.

Tiemens B.G., Ormel J., Jenner J.A., van der Meer K., Van Os T.W., van den Brink R.H., Smit A. \& van den Brink W. (1999). Training primary care physicians to recognize, diagnose, and manage depression: does it improve patient outcomes. Psychological Medicine 29, 833-844.

Trivedi M., Smith H. \& Rush A. (in press). Efficacy of antidepressants in primary care: a meta-analysis. Primary Care Psychiatry.

Tutty S., Simon G. \& Ludman E. (2000). Telephone counseling as an adjunct to antidepressant treatment in the primary care system: a pilot study. Effective Clinical Practice.

Üstïn \& Sartorius N. (1995). Mental lllness in General Health Care. John Wiley and Sons: New York.

VonKorff M., Ormel J., Katon W.J. \& Lin E.H.B. (1992). Disability and depression among high utilizers of health care. Archives of $G e-$ neral Psychiatry 49, 91-100.

Wells K.B. (1997). The Design of Partners in Care: Evaluating the Cost-effectiveness of Improving Care for Depression in Primary Care. RAND/UCLA Working paper No. P-122. Rand Corporation: Santa Monica, CA.

Wells K.B., Katon W., Rogers B. \& Camp P. (1994). Use of minor tranquilizers and antidepressant medications by depressed outpatients: Results from the Medical Outcomes Study. American Journal of Psychiatry 151, 694-700. 